\title{
ON THE SOLVABILITY OF NONLINEAR PROBLEM OF MAGNETIZATION
}

\author{
P. KATAUSKIS \\ Vilnius University \\ Naugarduko 24, 2600, Vilnius, Lithuania \\ E-mail: pranas@ieva.maf.vu.lt
}

\begin{abstract}
It is investigated the system of kinetic equations describing the magnetization of a medium consisting of single-domain particles. The system includes the nonlinear Landay-Lifschitz equation. The local existence of solution and its uniqueness in spaces $C^{k}(0, T ; X), \mathrm{X}$ denotes the Sobolev space, is proved.
\end{abstract}

\section{INTRODUCTION AND STATEMENT OF MAIN RESULT}

The dynamic Landay-Lifschitz equations [4] are often applied in the problems of magnetizations. Vl. Skakauskas in 1985 presented a new dynamic system of simultaneous equations describing the magnetization of a medium composed of single-domain particles [5]. There the nonlinear Landay-Lifschitz equation defines the motion of an individual single-domain particle in the magnetic field. There have been some solutions of the simple cases this problem [6]. Later the particular cases were studied in the various functional spaces [7; 3]. In [2] there was investigated the difference scheme applied to solve the nonlinear system of equations.

The purpose of this paper is to prove the existence and uniqueness of solution in a small time interval for the system nonlinear simultaneous equations in the general case.

We consider the boundary value problem of the system of equations

$$
\begin{aligned}
\frac{\partial u}{\partial t} & =a^{1} u \times(u \times v+v) \\
u & =u_{0}, \quad \text { for } t=0 \\
v & =a^{2} u+a^{3} w+a^{4} \frac{\partial z}{\partial x}
\end{aligned}
$$




$$
\begin{aligned}
w & =\int_{I} a^{5} u d y \\
L z & =\sum_{i=1}^{3}\left(\sum_{j=1}^{2} b_{i j} \frac{\partial w_{i}}{\partial x_{j}}+b_{i} w_{i}\right), \\
z & =\varphi, \quad \text { for } x \in \partial \Omega,
\end{aligned}
$$

where

$$
L z=: \sum_{i, j=1}^{2} \alpha_{i j} \frac{\partial^{2} z}{\partial x_{i} \partial x_{j}}+\sum_{i=1}^{2} \alpha_{i} \frac{\partial z}{\partial x_{i}}+\alpha z
$$

denotes an elliptic operator.

The motion of an individual single-domain particle in the magnetic field is described by the Landay-Lifschitz equation (1.1), $u_{0}$ defines the initial position of the particle. The equation (1.4) gives the magnetization of a medium. The last two equations determine the interaction between magnetic field of the medium and external magnetic field.

Here $\Omega \subset \mathbb{R}^{2}$ is the bounded domain with boundary $\partial \Omega, x=\left(x_{1}, x_{2}\right)$ is a point of $\Omega \cup \partial \Omega . \quad y$ is a point of the bounded domain $I \subset \mathbb{R}$ and let $Q=\Omega \times I . u(t, x, y), v(t, x, y), w(t, x), z(t, x)$ are unknown functions. Note that $u=\left(u_{1}, u_{2}, u_{3}\right), v=\left(v_{1}, v_{2}, v_{3}\right), w=\left(w_{1}, w_{2}, w_{3}\right)$ are threedimensional vectors, while $z$ is a scalar function. $a^{1}(t, x, y)$ is a given vector $a^{1}=\left(a_{1}^{1}, a_{2}^{1}, a_{3}^{1}\right)$ and $a^{k}(t, x, y), k=\overline{2,5}$ are given matrixes, namely, $a^{k}=\left\{a_{i j}^{k}\right\}_{i, j=1}^{3}$ for $k=2,3,5$ and $a^{4}=\left\{a_{i j}^{k}\right\}_{i, j=1}^{3,2}$. Scalar functions $b_{i j}(t, x, y)$, $b_{i}(t, x, y), i=1,2,3, j=1,2$ and $\varphi(t, x), \alpha(t, x), \alpha_{i}(t, x), \alpha_{i j}(t, x), i, j=1,2$ and a vector $u_{0}=u(0, x, y)$ are given data. The symbol $\times$ denotes the vector product of two vectors. All functions in this paper are real.

It is assumed that the operator $L$ is regular elliptic. It means that there exist two numbers $\mu_{1}, \mu_{2}>0$ such that the inequality

$$
\mu_{1}\left(\xi_{1}^{2}+\xi_{2}^{2}\right) \leq \sum_{i, j=1}^{2} \alpha_{i j}(t, x) \xi_{i} \xi_{j} \leq \mu_{2}\left(\xi_{1}^{2}+\xi_{2}^{2}\right)
$$

holds for all $\xi_{1}, \xi_{2} \in \mathbb{R}$ and for all $x \in \Omega, 0 \leq t<T$.

Let \|\|$_{2, \Omega}^{(l)}, l=0,1,2, \ldots$ denote the usual norm of the Sobolev space $W_{2}^{l}(\Omega)$ and $W_{2, \infty}^{l}(Q)$ is a Banach space with norm

$$
\|u\|_{2, \infty, Q}^{(l)}=\sup _{y \in I}\|u(y)\|_{2, \Omega}^{(l)} .
$$

We define a Banach space $C^{k}(0, T ; X)$ of $k$ times continuously differentiable functions in $[0 ; T]$ with values in a Banach space $X$ and with finite norm

$$
\sum_{i=1}^{k} \sup _{t \in[0, T]}\left\|u^{(i)}(t)\right\|_{X}
$$


where \|\|$_{X}$ denotes the norm in the space $X$.

As the main result we prove the following theorem.

Theorem 1.1. Let $\partial \Omega \subset C^{3}$ and $\varphi \in C\left(0, T ; W_{2}^{5 / 2}(\partial \Omega)\right), u_{0} \in W_{2, \infty}^{2,0}(Q)$. If $a^{k} \in C\left(0, T ; W_{2, \infty}^{2,0}(Q)\right), k=\overline{1,5} ; \alpha_{i j}, \alpha_{i}, \alpha \in C\left(0, T ; C^{1}(\Omega)\right), i, j=1,2$; $b_{i j}, b_{i} \in C\left(0, T ; W_{2}^{2}(\Omega)\right), i=1,2,3, j=1,2$ and the problem (1.5), (1.6) has a unique solution in the space $W_{2}^{3}(\Omega)$ for each fixed $t \leq T$, then there exists $T_{0}>0$ that the problem (1.1)-(1.6) for $T<T_{0}$ has a unique solution

$$
\begin{gathered}
u \in C^{1}\left(0, T ; W_{2, \infty}^{2,0}(Q)\right), v \in C\left(0, T ; W_{2, \infty}^{2,0}(Q)\right), \\
w \in C^{1}\left(0, T ; W_{2}^{2}(\Omega)\right), z \in C\left(0, T ; W_{2}^{3}(\Omega)\right) .
\end{gathered}
$$

\section{AUXILIARIES}

Lemma 2.1. Suppose that the conditions of smoothness of given data are satisfied. If $u \in C\left(0, T ; W_{2, \infty}^{2,0}(Q)\right)$ and the problem (1.5), (1.6) for each $0 \leq t<T$ has a unique solution in the space $W_{2}^{3}(\Omega)$, then

$$
v \in C\left(0, T ; W_{2, \infty}^{2,0}(Q)\right), w \in C^{1}\left(0, T ; W_{2}^{2}(\Omega)\right), z \in C\left(0, T ; W_{2}^{3}(\Omega)\right)
$$

and for all $0 \leq t<T$

$$
\|v(t)\|_{2, \infty, Q}^{(2)},\|w(t)\|_{2, \Omega}^{(2)},\|z(t)\|_{2, \Omega}^{(3)} \leq c_{1}\|u(t)\|_{2, \infty, Q}^{(2)} .
$$

Here a constant $c_{1}$ is independent of functions $u, v, w, z$.

Proof. We will assume there is a number $\mu$ such that

$$
\left\|a_{i}^{1}\right\|_{2, \Omega}^{(2)},\left\|a_{i j}^{k}\right\|_{2, \Omega}^{(2)},\left\|b_{i}\right\|_{2, \Omega}^{(2)},\left\|b_{i j}\right\|_{2, \Omega}^{(2)} \leq \mu
$$

for $k=\overline{2,5}, i, j=1,2,3$, for all $0 \leq t<T$ and for almost all $y \in I$.

By the Minkowski and Cauchy inequalities [8] from (1.4) it follows that

$$
\|w\|_{2, \Omega}^{2} \leq\left\{\int_{I}\left(\sum_{i, j=1}^{3}\left(\max _{\Omega}\left|a_{i j}^{5}\right|\right)^{2}\|u\|_{2, \Omega}^{2}\right)^{1 / 2} d y\right\}^{2}
$$

because $\left|a^{5} u\right| \leq \sum_{i, j=1}^{3}\left|a_{i j}^{5}\right|^{2}|u|^{2}$. Since $\Omega \subset \mathbb{R}^{2}$, by Sobolev's imbedding theorem,

$$
\max _{\Omega}|u| \leq c_{2}\|u\|_{2, \Omega}^{(2)}
$$


for $u \in W_{2}^{2}(\Omega)$ and

$$
\|u\|_{4, \Omega} \leq c_{3}\|u\|_{2, \Omega}^{(1)}
$$

for $u \in W_{2}^{1}(\Omega)$, where the constants $c_{1}, c_{2}$ do not depend on $u[8]$.

Taking into account (2.2), (2.3) we get the estimate

$$
\|w\|_{2, \Omega} \leq 3 \mu c_{2} m e s I\|u\|_{2, \Omega} .
$$

Next, we have

$$
\begin{gathered}
\left\|w_{x}\right\|_{2, \Omega}^{2} \leq \sum_{k=1}^{2}\left\{\int _ { I } \left[\left(\sum_{i, j=1}^{3}\left(\max _{\Omega}\left|a_{i j}^{5}\right|\right)^{2}\left\|u_{x_{k}}\right\|_{2, \Omega}^{2}\right)^{1 / 2}\right.\right. \\
\left.\left.+\left(\sum_{i, j=1}^{3}\left\|a_{i j x_{k}}^{5}\right\|_{2, \Omega}^{2}\left(\max _{\Omega}|u|\right)^{2}\right)^{1 / 2}\right] d y\right\}^{2} .
\end{gathered}
$$

This inequality combined with (2.2)-(2.4) gives us

$$
\left\|w_{x}\right\|_{2, \Omega} \leq 3 \mu c_{2} \operatorname{mesI}\left(2\|u\|_{2, \Omega}^{(2)}+\sqrt{2}\left\|u_{x}\right\|_{2, \Omega}\right) .
$$

Applying the Minkovski and Cauchy inequalities and using (2.2)-(2.4) we evaluate

$$
\left\|w_{x x}\right\|_{2, \Omega} \leq\left\{27 \mu\left(c_{2}+2 c_{3}\right)\|u\|_{2, \Omega}^{(2)}+9 c_{2} \mu\left\|u_{x x}\right\|_{2, \Omega}\right\} \text { mesI. }
$$

Now, estimates of $w, w_{x}$ and $w_{x x}$ imply the bound

$$
\|w(t)\|_{2, \Omega}^{(2)} \leq c_{4}\|u(t)\|_{2, \Omega}^{(2)},
$$

which is valid for all $t \in[0, T]$ and for almost $y \in I$. Here $c_{4}$ is a constant independent of $u$ and $w$.

Let $F$ denote the right-hand side of (1.5). We now will obtain the estimate of $F$. Using the Cauchy inequality and (2.2)-(2.4) we bound

$$
\left(\left\|b_{i} w_{i}\right\|_{2, \Omega}^{(1)}\right)^{2} \leq c_{2}^{2} \mu\left\{\mu\left\|w_{i}\right\|_{2, \Omega}^{2}+2 \sum_{k=1}^{2}\left[\mu c_{3}^{2}\left(\left\|w_{i}\right\|_{2, \Omega}^{(1)}\right)^{2}+\left\|w_{i x_{k}}\right\|_{2, \Omega}^{2}\right]\right\}, i=1,2,3 .
$$

The other term of $F$ is bounded above as follows

$$
\left(\left\|b_{i j} w_{i x_{j}}\right\|_{2}^{(1)}\right)^{2} \leq\left(\max _{\Omega}\left|b_{i j}\right|\right)^{2}\left\|w_{i x_{j}}\right\|_{2, \Omega}^{2}
$$




$$
+2 \sum_{k=1}^{2}\left\{\left(\max _{\Omega}\left|b_{i j}\right|\right)^{2}\left\|w_{i x_{j} x_{k}}\right\|_{2, \Omega}^{2}+\left\|b_{i j x_{k}}\right\|_{4, \Omega}^{2}\left\|w_{i x_{j}}\right\|_{4, \Omega}^{2}\right\}, i=1,2,3, j=1,2 .
$$

Because of $(2.3),(2.4)$ the right-hand side is less than

$$
\mu^{2}\left\{c_{2}\left\|w_{i x_{j}}\right\|_{2, \Omega}^{2}+2 \sum_{k=1}^{2}\left(c_{2}^{2}\left\|w_{i x_{j} x_{k}}\right\|_{2, \Omega}^{2}+c_{3}^{4}\left(\left\|w_{i x_{j}}\right\|_{2, \Omega}^{(1)}\right)^{2}\right)\right\}, i=1,2,3, j=1,2 .
$$

Finally, combining (2.6), (2.7) we find that

$$
\begin{gathered}
\left(\|F\|_{2, \Omega}^{(1)}\right)^{2} \leq 9 \mu^{2} \sum_{i=1}^{3} \sum_{j=1}^{2}\left\{c_{2}^{2}\left(\left\|w_{i x_{j}}\right\|_{2, \Omega}^{2}+\left\|w_{i}\right\|_{2, \Omega}^{2}\right)\right. \\
\left.+2 c_{2}^{2}\left(\sum_{k=1}^{2}\left\|w_{i x_{j} x_{k}}\right\|_{2, \Omega}^{2}+\left\|w_{i x_{j}}\right\|_{2, \Omega}^{2}\right)+2 c_{2}^{2} c_{3}^{2}\left(\left\|w_{i}\right\|_{2, \Omega}^{(1)}\right)^{2}+c_{3}^{4}\left(\left\|w_{i x_{j}}\right\|_{2, \Omega}^{(1)}\right)^{2}\right\} .
\end{gathered}
$$

Therefore

$$
\|F\|_{2, \Omega}^{(1)} \leq 3 \mu\left(3 c_{2}^{2}+4 c_{2}^{2} c_{3}^{2}+c_{3}^{4}\right)^{1 / 2}\|w\|_{2, \Omega}^{(2)} .
$$

This inequality combined with (2.5) for all $0 \leq t<T$ gives us

$$
\|F(t)\|_{2, \Omega}^{(1)} \leq c_{5}\|u(t)\|_{2, \Omega}^{(2)},
$$

where $c_{5}$ does not depend on $u$.

Hence for each fixed $t$ from $[0, T]$ the right-hand side of (1.5) is a function from the space $W_{2}^{1}(\Omega)$. Therefore by assumptions of Theorem the problem (1.5), (1.6) has a unique solution in the space $W_{2}^{3}(\Omega)$ and for each $0 \leq t<T$ the following inequality holds [1]

$$
\|z(t)\|_{2, \Omega}^{(3)} \leq c_{6}\|F(t)\|_{2, \Omega}^{(1)}+\|\varphi(t)\|_{2, \partial \Omega}^{(5 / 2)},
$$

where the constant $c_{6}$ is independent of $z$.

Further, applying (2.8) we have

$$
\|z(t)\|_{2, \Omega}^{(3)} \leq c_{7}\|u(t)\|_{2, \Omega}^{(2)}+c_{6}\|\varphi(t)\|_{2, \partial \Omega}^{(5 / 2)}
$$

for all $t \in[0, T)$.

Our next step is to estimate the function $v$. By the Cauchy inequality and (2.2)-(2.4) we obtain

$$
\left\|a^{2} u\right\|_{2, \Omega} \leq\left\{\sum_{i, j=1}^{3}\left(\max _{\Omega}\left|a_{i j}\right|\right)^{2}\|u\|_{2, \Omega}^{2}\right\}^{1 / 2} \leq 3 c_{2} \mu\|u\|_{2, \Omega}
$$


Similarly

$$
\left\|\left(a^{2} u\right)_{x_{k}}\right\|_{2, \Omega} \leq c_{2} \mu\left(\|u\|_{2, \Omega}^{(2)}+\left\|u_{x_{k}}\right\|_{2, \Omega}\right), k=1,2
$$

and

$$
\left\|\left(a^{2} u\right)_{x_{k} x_{l}}\right\|_{2, \Omega} \leq 27 \mu\left(c_{1}+2 c_{2}^{2}\right)\|u\|_{2, \Omega}^{(2)}+9 c_{1} \mu\left\|u_{x x}\right\|_{2, \Omega}, k, l=1,2 .
$$

From the last three inequalities we conclude that

$$
\left\|a^{2} u\right\|_{2, \Omega}^{(2)} \leq 3 \mu\left\{(11+3 \sqrt{3}) c_{2}+18 c_{3}^{2}\right\}\|u\|_{2, \Omega}^{(2)}
$$

The same inequality is true for the second term of right-hand side of (1.3) $a^{3} w$. It easy to verify that the third term of right-hand side of (1.3) is bounded above as follows

$$
\left\|\left(a^{4} z_{x}\right)\right\|_{2, \Omega}^{(2)} \leq 2 \mu\left\{(3 \sqrt{3}+4 \sqrt{6}) c_{2}+6 \sqrt{6} c_{3}^{2}\right\}\|z\|_{2, \Omega}^{(3)} .
$$

Now, from these estimates using (2.5), (2.9) we have

$$
\|v(t)\|_{2, \Omega}^{(2)} \leq c_{8}\|u(t)\|_{2, \Omega}^{(2)}
$$

for all $0 \leq t<T$ and for almost all $y \in I$. A constant $c_{8}$ depends only on given data and the numbers $\mu, c_{2}, c_{3}$.

From $(2.5),(2.9),(2.10)$ we get the estimates of Lemma 2.1. The continuity of functions $v, w, z$ with respect to $t$ follows from (2.1) and the properties of $u$.

Lemma 2.2. Let $u_{0} \in W_{2, \infty}^{2,0}(Q)$ and $a^{1}, v \in C\left(0, T ; W_{2, \infty}^{2,0}(Q)\right)$. Then $u \in$ $C^{1}\left(0, T ; W_{2, \infty}^{2,0}(Q)\right)$ and for all $0 \leq t<T$

$$
\|u(t)\|_{2, \infty, Q}^{(2)} \leq\left\|u_{0}\right\|_{2, \infty, Q}^{(2)}+c_{9} \int_{0}^{t}\left(\|u(\tau)\|_{2, \infty, Q}^{(2)}\right)^{2}\left(1+\|u(\tau)\|_{2, \infty, Q}^{(2)}\right) d \tau
$$

Here a constant $c_{9}$ does not depend on $u$.

Proof. In the space $C\left(0, T ; W_{2, \infty}^{2,0}(Q)\right)$ we consider the function $A(t, u)=$ $a^{1} u \times(u \times v+v)$. It easy to prove that $A(u, t) \in C\left(0, T ; W_{2, \infty}^{2,0}(Q)\right)$. Therefore the problem (1.1), (1.2) is equivalent to the equation

$$
u(t)=u_{0}+\int_{0}^{t} A(\tau) d \tau
$$


By Minkowski's inequality

$$
\begin{aligned}
& \|u(t)\|_{2, \infty, Q}^{(2)} \leq\left\|u_{0}(t)\right\|_{2, \infty, Q}^{(2)}+\int_{0}^{t}\left[\|A(\tau)\|_{2, \infty, Q}\right. \\
& \left.+\sum_{k=1}^{2}\left\|A_{x_{k}}(\tau)\right\|_{2, \infty, Q}+\sum_{k, l=1}^{2}\left\|A_{x_{k} x_{l}}(\tau)\right\|_{2, \infty, Q}\right] d \tau .
\end{aligned}
$$

We will estimate each norm separately.

Using the Cauchy inequality and (2.2)-(2.4) we bound

$$
\|A\|_{2, \Omega} \leq \sqrt{3} c_{2}^{2} \mu\left(1+c_{1}\|u\|_{2, \Omega}^{(2)}\right)\|u\|_{2, \Omega}^{(2)}\|v\|_{2, \Omega}
$$

For the norm of the first derivative we obtain

$$
\begin{gathered}
\left\|A_{x_{k}}\right\|_{2, \Omega} \leq \sqrt{3} c_{2}^{2} \mu\left\{\left(1+c_{2}\|u\|_{2, \Omega}^{(2)}\right)\|u\|_{2, \Omega}^{(2)}\|v\|_{2, \Omega}^{(2)}\right. \\
\left.+\left(1+2 c_{2}\|u\|_{2, \Omega}^{(2)}\right)\|v\|_{2, \Omega}^{(2)}\left\|u_{x_{k}}\right\|_{2, \Omega}+\left(1+c_{2}\|u\|_{2, \Omega}^{(2)}\right)\|u\|_{2, \Omega}^{(2)}\left\|v_{x_{k}}\right\|_{2, \Omega}\right\}, k=1,2 .
\end{gathered}
$$

The norm of the second derivative is bounded above as follows

$$
\begin{gathered}
\left\|A_{x_{k} x_{l}}\right\|_{2, \Omega} \leq \sqrt{3} c_{2} \mu\left\{c_{2}\left(c_{2}+12 c_{3}^{2}\right)\left(\|u\|_{2, \Omega}^{(2)}\right)^{2}\|v\|_{2, \Omega}^{(2)}+\left(c_{2}+6 c_{3}^{2}\right)\|u\|_{2, \Omega}^{(2)}\|v\|_{2, \Omega}^{(2)}\right. \\
+c_{2}\left(1+c_{2}\|u\|_{2, \Omega}^{(2)}\right)\|v\|_{2, \Omega}^{(2)}\left\|u_{x_{k} x_{l}}\right\|_{2, \Omega}+c_{2}\|u\|_{2, \Omega}^{(2)}\left[c_{2}\left\|u_{x_{k} x_{l}}\right\|_{2, \Omega}\|v\|_{2, \Omega}^{(2)}\right. \\
\left.\left.+\left(1+c_{2}\|u\|_{2, \Omega}^{(2)}\right)\left\|v_{x_{k} x_{l}}\right\|_{2, \Omega}\right]\right\}, k, l=1,2 .
\end{gathered}
$$

Now, the estimates of $A, A_{x_{k}}$ and $A_{x_{k} x_{l}}$ imply that the integrand expression in (2.12) for all $0 \leq t<T$ and almost all $y \in I$ is less than

$$
c_{10}\|u(t)\|_{2, \Omega}^{(2)}\|v(t)\|_{2, \Omega}^{(2)}\left(1+\|u(t)\|_{2, \Omega}^{(2)}\right)
$$

where $c_{10}$ does not depend on $u$ and $v$.

Finally, taking into account (2.1), we get (2.11).

Lemma 2.3. Under the assumptions of Theorem 1.1 there exists $T_{0}>0$ that for all $T<T_{0}$

$$
\max _{t \in[0, T]}\left\{\|u(t)\|_{2, \infty, Q}^{(2)},\|v(t)\|_{2, \infty, Q}^{(2)},\|w(t)\|_{2, \Omega}^{(2)},\|z(t)\|_{2, \Omega}^{(2)}\right\} \leq c_{11}
$$

The constant $c_{11}$ is independent of $u, v, w, z$. 
Proof. Let

$$
\beta(t)=\left\|u_{0}\right\|_{2, \infty, Q}^{(2)}+c_{9} \int_{0}^{t}\left(\|u(\tau)\|_{2, \infty, Q}^{(2)}\right)^{2}\left(1+\|u(\tau)\|_{2, \infty, Q}^{(2)}\right) d \tau .
$$

This implies

$$
\frac{d \beta}{d t}=c_{9}\left(\|u(t)\|_{2, \infty, Q}^{(2)}\right)^{2}\left(1+\|u(t)\|_{2, \infty, Q}^{(2)}\right) .
$$

From the definition of $\beta$ and (2.11) it follows that

$$
\|u(t)\|_{2, \infty, Q}^{(2)} \leq \beta(t) .
$$

Therefore

$$
\frac{d \beta}{d t} \leq c_{9} \beta^{2}(1+\beta)
$$

and in addition

$$
\beta_{0}=\beta(0)=\left\|u_{0}\right\|_{2, \infty, Q}^{(2)} .
$$

The solution of the differential problem

$$
\begin{gathered}
\frac{d \beta}{d t}=c_{9} \beta^{2}(1+\beta), \\
\beta_{0}=\beta(0)
\end{gathered}
$$

is an increasing function which majorize the solution of the problem (2.15), (2.16). Therefore there exists a number $T_{0}>0$ such that the function $\beta(t)$ is bounded in the interval $[0, T]$ for all $T<T_{0}$.

Now the statement of Lemma 2.3 follows from (2.14) and (2.1).

\section{PROOF OF THEOREM}

In the space $C\left(0, T ; W_{2, \infty}^{2,0}(Q)\right)$ we define the operator

$$
B(u(t))=u_{0}+\int_{0}^{t} a^{1} u(\tau) \times(u(\tau) \times v(\tau)+v(\tau)) d \tau .
$$

We will prove that $B$ is a contractive operator. Let $u^{1}, u^{2}$ be two functions of $C\left(0, T ; W_{2, \infty}^{2,0}(Q)\right)$, while $v^{1}, v^{2}$ are the corresponding solutions of (2.3)-(2.6). Let $\eta=u^{2}-u^{1}$ and $\beta=v^{2}-v^{1}$. Then

$$
B\left(u^{2}\right)-B\left(u^{1}\right)=\int_{0}^{t} \psi(\tau) d \tau
$$


where

$$
\begin{gathered}
\psi=a^{1} u^{2} \times\left(u^{2} \times v^{2}+v^{2}\right)-a^{1} u^{1} \times\left(u^{1} \times v^{1}+v^{1}\right) \\
=a^{1} \eta \times\left(u^{2} \times v^{2}+v^{2}\right)+a^{1} u^{1} \times\left(\eta \times v^{2}+u^{1} \times \beta+\beta\right) .
\end{gathered}
$$

We obtain the estimate of $\psi$ similarly to the estimates of lemmas. Using the Minkowski and Cauchy inequalities and applying (2.2)- (2.4) we have

$$
\begin{gathered}
\|\psi\|_{2, \Omega} \leq \sqrt{3} c_{2}^{2} \mu\left\{\left(1+c_{1}\left\|u^{2}\right\|_{2, \Omega}^{(2)}\right)\left\|v^{2}\right\|_{2, \Omega}^{(2)}\|\eta\|_{2, \Omega}\right. \\
\left.\left.+\left[c_{2}\left\|v^{2}\right\|_{2, \Omega}^{(2)}\|\eta\|_{2, \Omega}+\left(1+c_{2}\left\|v^{1}\right\|_{2, \Omega}^{(2)}\right)\|\beta\|_{2, \Omega}\right)\right]\left\|v^{1}\right\|_{2, \Omega}^{(2)}\right\} .
\end{gathered}
$$

The first derivatives of $\psi$ we bound

$$
\begin{gathered}
\left\|\psi_{x_{k}}\right\|_{2, \Omega} \leq \sqrt{3} c_{2}^{2} \mu\left\{\left(1+c_{2}\left\|u^{2}\right\|_{2, \Omega}^{(2)}\right)\left\|v^{2}\right\|_{2, \Omega}^{(2)}\left(\|\eta\|_{2, \Omega}^{(2)}+\left\|\beta_{x_{k}}\right\|_{2, \Omega}\right)\right. \\
+\left[c_{2}\|\eta\|_{2, \Omega}^{(2)}\left\|v^{2}\right\|_{2, \Omega}^{(2)}+\left(1+c_{2}\left\|u^{1}\right\|_{2, \Omega}^{(2)}\right)\|\beta\|_{2, \Omega}^{(2)}\right]\left(\left\|u^{1}\right\|_{2, \Omega}^{(2)}+\left\|u_{x_{k}}^{1}\right\|_{2, \Omega}\right) \\
+\left[c_{2}\left\|u_{x_{k}}^{2}\right\|_{2, \Omega}\left\|v^{2}\right\|_{2, \Omega}^{(2)}+\left(1+c_{2}\left\|u^{2}\right\|_{2, \Omega}^{(2)}\right)\left\|v_{x_{k}}^{2}\right\|_{2, \Omega}\right]\|\eta\|_{2, \Omega}^{(2)}+c_{2}\left(\left\|\eta_{x_{k}}\right\|_{2, \Omega}\left\|v^{2}\right\|_{2, \Omega}^{(2)}\right. \\
+\|\eta\|_{2, \Omega}^{(2)}\left[\left\|v_{x_{k}}^{2}\right\|_{2, \Omega}+\left\|u_{x_{k}}^{1}\right\|_{2, \Omega}\|\beta\|_{2, \Omega}^{(2)}+\left(1+c_{2}\left\|u^{1}\right\|_{2, \Omega}^{(2)}\right)\left\|\beta_{x_{k}}\right\|_{2, \Omega}\right\}, k=1,2 .
\end{gathered}
$$

The second derivatives of $\psi$ are estimated as follows

$$
\begin{aligned}
& \left\|\psi_{x_{k} x_{l}}\right\|_{2, \Omega} \leq \sqrt{3} c_{2} \mu\left\{\left(1+c_{1}\left\|u^{2}\right\|_{2, \Omega}^{(2)}\right)\left\|v^{2}\right\|_{2, \Omega}^{(2)}\left[\left(c_{2}+2 c_{3}^{2}\right)\|\eta\|_{2, \Omega}^{(2)}+c_{1}\left\|\eta_{x_{k} x_{l}}\right\|_{2, \Omega}\right]\right. \\
& +c_{2}\left[\|\eta\|_{2, \Omega}^{(2)}\left\|v^{2}\right\|_{2, \Omega}^{(2)}+\left(1+\left\|u^{1}\right\|_{2, \Omega}^{(2)}\right)\|\beta\|_{2, \Omega}^{(2)}\right]\left[\left(c_{2}+2 c_{3}^{2}\right)\left\|u^{1}\right\|_{2, \Omega}^{(2)}+c_{2}\left\|u_{x_{k} x_{l}}^{1}\right\|_{2, \Omega}\right] \\
& +4 c_{3}^{2}\left[\left(1+\left\|u^{2}\right\|_{2, \Omega}^{(2)}\right)\left\|v^{2}\right\|_{2, \Omega}^{(2)}\|\eta\|_{2, \Omega}^{(2)}+\left(2 c_{2}\|\eta\|_{2, \Omega}^{(2)}\left\|v^{2}\right\|_{2, \Omega}^{(2)}+\left(1+2 c_{2}\left\|u^{1}\right\|_{2, \Omega}^{(2)}\right)\|\beta\|_{2, \Omega}^{(2)}\right)\right. \\
& \left.\times\left\|u^{1}\right\|_{2, \Omega}^{(2)}\right]+c_{2}\|\eta\|_{2, \Omega}^{(2)}\left[\left(c_{2}\left\|u_{x_{k} x_{l}}^{2}\right\|_{2, \Omega}+2 c_{3}\left\|u^{2}\right\|_{2, \Omega}^{(2)}\right)\left\|v^{2}\right\|_{2, \Omega}^{(2)}+\left(1+c_{2}\left\|u^{2}\right\|_{2, \Omega}^{(2)}\right)\right. \\
& \left.\times\left\|v_{x_{k} x_{l}}^{2}\right\|_{2, \Omega}\right]+c_{2}\left\|u^{1}\right\|_{2, \Omega}^{(2)}\left[\left(c_{2}\left\|\eta_{x_{k} x_{l}}\right\|_{2, \Omega}+2 c_{3}^{2}\|\eta\|_{2, \Omega}^{(2)}\right)\left\|v^{2}\right\|_{2, \Omega}^{(2)}+c_{2}\|\eta\|_{2, \Omega}^{(2)}\left\|v_{x_{k} x_{l}}^{2}\right\|_{2, \Omega}\right. \\
& \left.\left.+\left(c_{2}\left\|u_{x_{k} x_{l}}^{1}\right\|_{2, \Omega}+2 c_{3}^{2}\left\|u^{1}\right\|_{2, \Omega}^{(2)}\right)\|\beta\|_{2, \Omega}^{(2)}+\left(1+c_{2}\left\|u^{1}\right\|_{2, \Omega}^{(2)}\right)\left\|\beta_{x_{k} x_{l}}\right\|_{2, \Omega}\right]\right\}, k, l=1,2 .
\end{aligned}
$$

These estimates are valid for all $0 \leq t<T$ and for almost all $y \in I$. The last two inequalities combined with (2.11) gives us

$$
\|\psi(t)\|_{2, \Omega}^{(2)} \leq c_{12}\|\eta(t)\|_{2, \Omega}^{(2)}+c_{13}\|\beta(t)\|_{2, \Omega}^{(2)}
$$

for all $0 \leq t<T$ and for almost all $y \in I$. Here $c_{12}, c_{13}$ do not depend on $\eta$ and $\beta$. From the equation (2.3) and the inequality (2.10) we obtain

$$
\|\beta(t)\|_{2, \Omega}^{(2)} \leq c_{14}\|\eta(t)\|_{2, \Omega}^{(2)}
$$


for all $0 \leq t<T$ and for almost all $y \in I$. Therefore from here and (3.2) we get the estimate

$$
\|\psi(t)\|_{2, \infty, Q}^{(2)} \leq c_{15}\|\eta(t)\|_{2, \infty, Q}^{(2)}
$$

for all $0 \leq t<T$ with the constant $c_{15}$ independent of $\eta$. Since $\eta=u^{2}-u^{1}$, we conclude from (3.1) and (3.3) that

$$
\left\|B\left(u^{2}\right)-B\left(u^{1}\right)\right\|_{2, \infty, Q}^{(2)} \leq c_{15} \int_{0}^{t}\left\|u^{2}-u^{1}(\tau)\right\|_{2, \infty, Q}^{(2)} d \tau
$$

for all $0 \leq t<T$ and $c_{15}$ does not depend on $u^{1}, u^{2}$.

Thus for $t<1 / c_{15}, B(u(t))$ is the contractive operator in the space $C\left(0, T ; W_{2, \infty}^{2,0}(Q)\right)$. Now the statement of Theorem follows from Lemmas $2.1,2.2$.

\section{REFERENCES}

[1] S. Agmon, S. Douglis and L. Nirenberg. Estimates near the boundary for solutions of elliptic partial differential equations satisfying general boundary conditions. Inostrannaja literatura, Moscow, 1990. (in Russian)

[2] P.Katauskis. Difference scheme for the nonlinear problem of magnetization. Lith. Math. J., 32 (2), 1992, 188 - 197.

[3] P.Katauskis. Unique solvability of the medium magnetization type composed of singledomain particles in the $L_{p}$ space. Lith. Math. J., 30 (1), 1990, $71-80$.

[4] L. Landay-E. Lifschitz. On theory of magnetic permeability in feromagnetic bodies. Phys. Zeitschr. Sowjetunion, 8, 1935, $183-189$.

[5] V.Skakauskas. The kinetic equations of the single-domain field magnetization. Lith. Math. J., 25 (1), 1985, $161-173$.

[6] V. Skakauskas. The some exact solutions of the ferromagnetic body behavior problem in the given field on the infinity. Lith. Math. J., 29 (2), 1989, $377-384$.

[7] V. Skakauskas. Unique solvability of the problem of the medium, magnetization type composed of single domain particles. Differential equations and their application, 42, $1988,74-86$.

[8] S. L. Sobolev. Selected questions of the theory of functional spaces and generalized functions. Nauka, Moscow, 1989. (in Russian) 


\section{NETIESINIO İMAGNETINIMO UŽDAVINIO} IŠSPRENDŽIAMUMAS

\section{P. KATAUSKIS}

Nagrinëjama netiesinių lygčių sistema, aprašanti medžiagos, sudarytos iš viendomenių dalelių, įmagnetinimą. Matematinis modelis pasiūlytas V. Skakausko $1973 \mathrm{~m}$. Atskiros dalelès judèjimą magnetiniame lauke apibrèžia netiesinè vektorinė Landay-Lifšico lygtis. Medžiagos i̇magnetinimas aprašomas Maksvelo lygtimis. Tiriamoji lygčių sistema gauta i̇vedus vektorini gradientą. Irodyta lokalaus pagal laiką sprendinio egzistencija ir vienatis erdvèse $C\left(0, T^{0}, X\right)$, čia $X-$ Sobolevo erdvès.

Teiginys pagrindžiamas parodant, kad tam tikras operatorius erdvëje

$C\left(0, T^{0}, X\right)$ yra suspaudžiantysis, kai laiko intervalas yra trumpas. İrodymas paremtas aprioriniais įverčiais, taikomos įdejjimo teoremos, todèl gautas rezultatas teisingas, kai nagrinèjama aprèžta sritis plokštumoje. 